Nigeria [sometimes I use another West African name]. What do you advise me to do to avoid tropical health hazards?" (In no case did I disclose my profession.) In a few instances I have been recommended (apart, of course, from the mandatory vaccinations) to consult my own doctor or the local public health department. That is good advice. It was frightening, however, to be told by three branches of a certain world-wide travel agency (in Dublin, in Richmond, Virginia, and in Philadelphia) that there was no malaria in West Africa and that no precautions were necessary. In Raleigh, North Carolina, and at another agency in Richmond I was given the same misinformation. In Knoxville, Tennessee, an elderly agent went further. "If you are vaccinated for yellow fever," he said, "that will take care of malaria." $\mathrm{He}$ added, "Some people take quinine but the yellow fever shot is all you need!"

The International Passengers' Consumer Association as its first publication produced a simple guide for travellers to the tropics and subtropics, written for us by Professor Leonard Bruce-Chwatt; and every member of the association receives one as soon as he joins. Talking with some professional travelwriters in the United States I found considerable interest in this particular aspect of our "consumer interests" in travel, and it is probable that, through their writings in the future, the risks-and how to protect against them-may receive wider non-medical coverage.

This association plans to try hard to give greater prominence to the problem so well outlined by Professor Maegraith, both within its own growing membership and to the public at large and through the travel trade -if they will co-operate.-I am, etc.

GEOFFREY MYERS International Passengers' Consumer Association Shannon Airport Industrial Estate, Limerick, Ireland

\section{Prevention of Pulmonary Embolism}

SIR,-Like Mr. C. V. Ruckley and his colleagues (19 May, p. 419) I thought your leading article ( 7 April, p. 1) was excellent, but $I$ am on their side in criticizing your conclusion from the practical point of viewno fault can be found with it theoretically.

I think they are right in advising surgeons to use one or more of the available prophylactic methods routinely, and not to wait for the final proof which only the appropriate clinical trials can provide. To support this advice let me say that since we started to stimulate the calf muscles electrically during the operation seven years ago we have only suffered one fatal pulmonary embolism, after prostatectomy; at necropsy the clot was seen to have come from the left internal iliac vein.

To concentrate the attention of the surgeon on early diagnosis and vigorous treatment is, in my opinion, a mistake. Early diaonosis is poscible only in special units, not in ordinary regional hospitals. Using the ${ }^{125}$ I-fibrinogen test it takes 12 minutes to scan each patient. Therefore to scan a surgical unit of 56 beds (like ours) would take 14 hours a davanyway, who is to do the scanning? The laboratory detection of early fibrin degradation products is even less practical. Gel chromatography ${ }^{2}$ is good, but needs a computer, among other things; protamine sulphate serial dilution test ${ }^{3}$ is inferior but simpler. Sevitt and Gallagher ${ }^{4}$ found that a special laboratory unit was needed to produce even such a simple thing as a daily prothrombin time-our laboratories refuse to provide a daily prothrombin time, so what hope is there of their providing the vastly more complicated, time-consuming, tests for fibrin degradation products?

I am worried by this concentration on early diagnosis for another reason: it focuses the surgeon's attention on the postoperative period. In 1964 we discovered that serious venous stagnation developed in the lower limbs while the operation was in progress. Later isotope studies established that thrombosis was present in the immediate postoperative period. ${ }^{6}$

Finally I would like to reinforce $\mathrm{Mr}$. Ruckley's advice by saying that whicheve method appeals to a particular surgeonpneumatic compression, electrical calf stimulation, etc.,-it is while he is operating that he should be thinking about deep venous thrombosis, and that if he selects heparin (the dose is of secondary importance) he must begin its administration before he makes his incision. Looking for it in the ward days later is useless in prevailing hospital conditions.I am, etc., Bromsgrove General Hospital,
Bromsgrove, Worcs

F. S. A. DORAN

1 Kakkar, V. V., in Thrombo-Embolism-Dignosis p. 101 . 1972.

2 Fletcher, A. P., Alkjaersig, N., and O'Brien, J., ibid, p. 25.

3 Gurewich, V., ibid, p. 39.

Sevitt. S., and Gallagher, N. G., Lancet, 1959, Doran, F. S. A., Drury, M., and Sivyer, A., Doran, F. S. A., Drury, M., and Sivyer, A.,
British fourmal of Surgery, 1964, 51, 486.
Flanc. C. Kakkar, V. V., and Clarke, M. B.,
British fournal of Surgery, 1968, 55, 742. Negus, D., Pinto, D. J, Le Quesne, L. P., Brown,

Ne, and Chapman,
gery, 1968, 55, 835 .

SIR,-I find it difficult to accept the suggestion in your leading articles (7 April, p. 1) that only four or five fatal cases of thromboembolism are observed per thousand surgical patients. In reviewing now more than 20,000 major operations ${ }^{1}$ in a period of over 12 years I reported an incidence as confirmed at necropsy of one such fatality in 90 procedures, representing 12 such deaths, or three times the above quoted number of such episodes. Perhaps you are justified in being critical of the results reported in the ${ }^{125} \mathrm{I}$ fibrinogen uptake controlled studies as being too small and inconclusive since they also lack the evidence of fatal thromboembolism. You may also be unimpressed by my own results, a study initiated by $\mathbf{m e}^{2}$ in August 1960 and now totalling 1,600 often at-risk major operations using small prophylactic doses of aqueous sodium heparin subcutaneously, with fatal outcome as the final evaluation. To date there have been two fatal cases of thromboembolism in our on-going study confirmed at necropsy, both unusual and instructive. Both patients were elderly, 75 and 96 years respectively, with hip fractures who were immobilized for eight days before our heparin prophylaxis was instituted the night before surgery. This has taught us to heparinize such individuals immediately and continue through surgery.

My small-dose prophylactic heparin rou- $\begin{aligned} & \text { Hoylake, } \\ & \text { Wirral, Cheshire }\end{aligned}$ tine controlled by the modified Dale and Laidlaw coagulometer is truly "free of side effects, cheap, and simple," as stipulated in your article, compared with the dosage sohedule advocated by Kakkar et al..$^{3}$ Perhaps my recommended routine will not be the final answer, but it has much to recommend it and, as O'Brien ${ }^{4}$ concedes, small-dose heparin is effective, though he fails to understand why. However, he like all others in their confirmatory reports makes no mention of what prompted me as a pathologist to institute my heparin prophylaxis using the operative patient as an experimental subject -namely, the pulmonary megakaryocytes and their initiation of the hypercoagulable state and thrombosis. I believe an appreciation of the latter would greatly simplify the whole approach to heparin prophylaxis.

I do believe that your last comment, that "more value will be obtained from screening early diagnosis, and vigorous treatment than from the uncritical use of unproved methods of prophylaxis," is truly, to borrow a phrase from your article "akin to shutting the stable door after the horse has bolted" for in most instances the last approach has proved to be just too little and too late.

In any event, whether there are four or five or 12 fatal thromboembolisms per thousand operations, it is neveretheless a shocking experience for all, for it is so unexpected and so suddenly fatal. Finally, I firmly believe that any reduction in these fatalities is not only desirable but mandatory since the means of prevention are at hand.-I am, etc.,

J. G. SHARNOFF

Department of Pathology

Mount Vernon Hospital

Mount Vernon, New York

Sharnoff, J. G., and DeBlasio, G., Lancet, 1970, 2,1006

Sharnoff. J. G., Kass, H. H., and Mistica, B.,
Surgery Gynecology and Obstetrics, 1962, 115, Surgery.

Kakkar, V. V., et al., Lancet, 1972, 2, 101.
O'Brien, J. R., American Heart fournal, 1973, 85, 435

SIR,-Forty years' experience has convinced me that fatal pulmonary embolism can be reduced almost to vanishing point by a simple postoperative routine embracing posture and exercises. After operation the foot of the bed is raised on 9-in $(23-\mathrm{cm})$ blocks for a minimum of 48 hours, during which the head is kept low. A cage is used to raise the bed-clothes and give freedom to the legs. From the earliest possible moment the patient is instructed, urged, and encouraged to move his ankles and knees actively, intermittently throughout the day. Physiotherapists are invaluable and become enthusiastic. They visit the wards daily to supervise deep breathing and to help those in need with passive exercises and massage.

Early "ambulation" (which we also practise) speeds convalescence but does not control embolism. When it became fashionable we switched away from our routine and embolism returned to our wards. Early "rising-from-bed-to-sit-in-a-chair" would be a better description; the sitting posture encourages venous stasis in the legs rather than the reverse.

Our regimen may lack statistical validity but it works and has the virtue of simplicity. Perhaps it is too simple!-I am, etc. 